\title{
SEGURIDAD CIUDADANA \\ (hacia una radiografía de la seguridad subjetiva en Guadalajara)
}

\author{
Citizen Security \\ (Towards a radiography of the subjective security in Guadalajara)
}

Marcos Pablo Moloeznik ${ }^{*}$

\section{Sumario}

1. A manera de introducción. 2. Universo objeto de estudio. 3. Segunda aproximación: seguridad subjetiva de acuerdo con los resultados del proyecto Justiciabarómetro 2009. 4. Tercera aproximación: seguridad subjetiva de conformidad con el estudio cualitativo Radiografía Ciudadana de Guadalajara. 5. Conclusiones.

Resumen. Se trata de un estudio sobre la seguridad subjetiva o percepción de inseguridad ciudadana en Guadalajara, a partir los siguientes tres enfoques: (a) los resultados de las encuestas nacionales sobre inseguridad del instituto ciudadano de estudios sobre la inseguridad (icesi); (b) el imaginario de los policías municipales preventivos de la zona metropolitana de Guadalajara sobre este complejo fenómeno, que se recoge en el proyecto justiciabarómetro; $y$, c) fundamentalmente, el estudio cualitativo que se desprende del esfuerzo titulado radiografía ciudadana de Guadalajara.

Una vez centrado el trabajo en este último, se intenta demostrar que existe una correlación relativa entre la calidad de los servicios públicos municipales y la situación de seguridad/ inseguridad percibida por los propios vecinos; en otras palabras, cabe preguntarse si la prestación de mejores servicios tiene su correlato en un sentimiento de protección y seguridad entre los residentes, y si un déficit de servicios o de mala calidad, redundan en una situación de inseguridad, de acuerdo con la opinión de los propios colonos. Cabe destacar que esta relación inextricable entre servicios y seguridad subjetiva, contempla especialmente los servicios de agua, vías generales de comunicación y electricidad, incluyendo el alumbrado público y el estado de las calles.

Palabras clave: Seguridad - seguridad subjetiva - percepción de inseguridad ciudadana Guadalajara.

Abstract. It is an study concerning citizens' subjective security or insecurity perception in Guadalajara, from the following three approaches: (a) the results of the national survey on insecurity citizen institute for studies on insecurity (icesi), (b) the imagination of the municipal preventive police from the metropolitan area of Guadalajara about this complex phenomenon, which is included in the project justiciabarómetro, and c) mainly, the qualitative study derivated from the effort tittled Guadalajara's radiography citizen.

\footnotetext{
$\overline{1^{\star}}$ Profesor-Investigador Titular “C”, Departamento de Estudios Políticos, Centro Universitario de Ciencias Sociales y Humanidades de la Universidad de Guadalajara.
} 
Once centered the work in this last one, the $>\emptyset$ study tries to demostrate that there is a relative correlation between the municipal public quality services and the security/insecurity situation percibed by the residents themselves; in other words, the question is whether the provision of better services has its counterpart in a feeling of safety and security among residents, and if a deficit or poor quality services, result in an unsafe condition, according to the opinion of the settlers themselves. It is important to point that this relation between subjective security and services, contemplates specially the following services: water, comunication means and electricity, including streer lightning and the streets state.

Key words: Security - subjective security - citizen insecurity perception - Guadalajara city.

\section{A MANERA DE INTRODUCCIÓN}

El artículo 21 constitucional define a la seguridad pública como una competencia concurrente, es decir, una función que comparten la federación, las entidades federativas y los municipios en sus respectivos ámbitos de competencia. Política sectorial, cuyos resultados se reflejan en las estadísticas oficiales (seguridad objetiva), que lejos están de recoger la percepción de los ciudadanos; el sentimiento de seguridad o, por el contrario, de indefensión de la población (seguridad subjetiva).

De ahí la importancia de trabajos cualitativos como Radiografía Ciudadana de Guadalajara, producto de la combinación de juntas vecinales - con grupos de enfoque- en todas las colonias de la capital del estado de Jalisco, entrevistas a líderes y actores sociales clave, y observaciones directas de campo de los investigadores participantes.

La base de datos así generada, permite llevar a cabo un estudio único sobre la seguridad subjetiva o percepción de inseguridad ciudadana en Guadalajara; se trata de una investigación pionera, porque los antecedentes -que, por cierto, se toman en cuenta- no están centrados en la opinión de los ciudadanos de los barrios y colonias del municipio de Guadalajara. Efectivamente, los resultados de las Encuestas Nacionales sobre Inseguridad del Instituto Ciudadano de Estudios sobre la Inseguridad, se basan en la zona metropolitana de Guadalajara (ZMG) que incluye a Guadalajara, pero también a otros cinco municipios; mientras que el Proyecto Justiciabarómetro solo toma en cuenta la percepción de los policías municipales preventivos de la ZMG, a la sazón como principales operadores del sistema de justicia penal.

A partir de la información generada por Radiografía Ciudadana de Guadalajara, se intenta demostrar que existe una correlación relativa entre la calidad de los servicios públicos municipales y la situación de seguridad/inseguridad percibida por los propios vecinos; en otras palabras, cabe preguntarse si la prestación de mejores servicios tiene su correlato en un sentimiento de protección y seguridad entre los residentes, y si un déficit de servicios o de mala calidad, redundan en una situación de inseguridad, de acuerdo con la opinión de los propios colonos. Cabe destacar que esta relación inextricable entre el desempeño o gestión de los gobiernos municipales y seguridad subjetiva, contempla especialmente los servicios de agua, vías generales de comunicación y electricidad, incluyendo el alumbrado público y el estado de las calles.

El derecho a la seguridad consagrado en el artículo 21 de la Carta Magna va más allá de la obligación, por parte del estado, de dar cumplimiento a esa función pública; se trata del derecho a vivir sin miedo, a gozar de los espacios públicos y a sentirse en un entorno social seguro: seguridad ciudadano-céntrica, por ser la seguridad de la persona humana su principal finalidad. El 
análisis que se presenta a continuación parte de esta concepción de seguridad ciudadana ybusca presentar y evaluar la situación que guarda en el municipio de Guadalajara en la actualidad.

2. UNIVERSO OBJETO DE ESTUDIO DE ACUERDO CON EL INSTITUTONACIONALDE ESTADÍSTICA, GEOGRAFÍA E INFORMÁTICA (INEGI), EN 2005 LA POBLACIÓN DEL ESTADO DE JALISCO ERA DE $6,752,113$ HABITANTES. ${ }^{2}$ DURANTE ESE MISMO AÑO, EL MUNICIPIO CON MAYOR PORCENTAJE DE HABITANTES ERA GUADALAJARA CON $\mathbf{2 3 . 7 \%}(1,600,940)$, SEGUIDODE ZAPOPAN CON $\mathbf{1 7 . 1 \%}(1,155,790)$ Y DE TLAQUEPAQUE CON 8.3 POR CIENTO $(563,006){ }^{3}$

En tanto que, para el Consejo Estatal de Población (COEPO), actualmente Jalisco tiene una población de 7,037,085 de habitantes, de los cuales 4,328,584 residen en la zona metropolitana de Guadalajara (ZMG), con una clara tendencia a la disminución de la población de la capital de Jalisco, de conformidad con las proyecciones del propio COEPO, en contraste con Zapopan, Tlaquepaque, Tonalá, Tlajomulco de Zúñiga y El Salto, en franco crecimiento poblacional. ${ }^{4}$

Recapitulando, dar cuenta de la radiografía de la seguridad subjetiva en Guadalajara, impone conocer la percepción de poco más de un millón 600 mil personas de carne y hueso que residen de manera permanente en la Perla de Occidente.

Primera aproximación: seguridad subjetiva de acuerdo con el Instituto Ciudadano de Estudios sobre la Inseguridad, A.C. (ICESI).

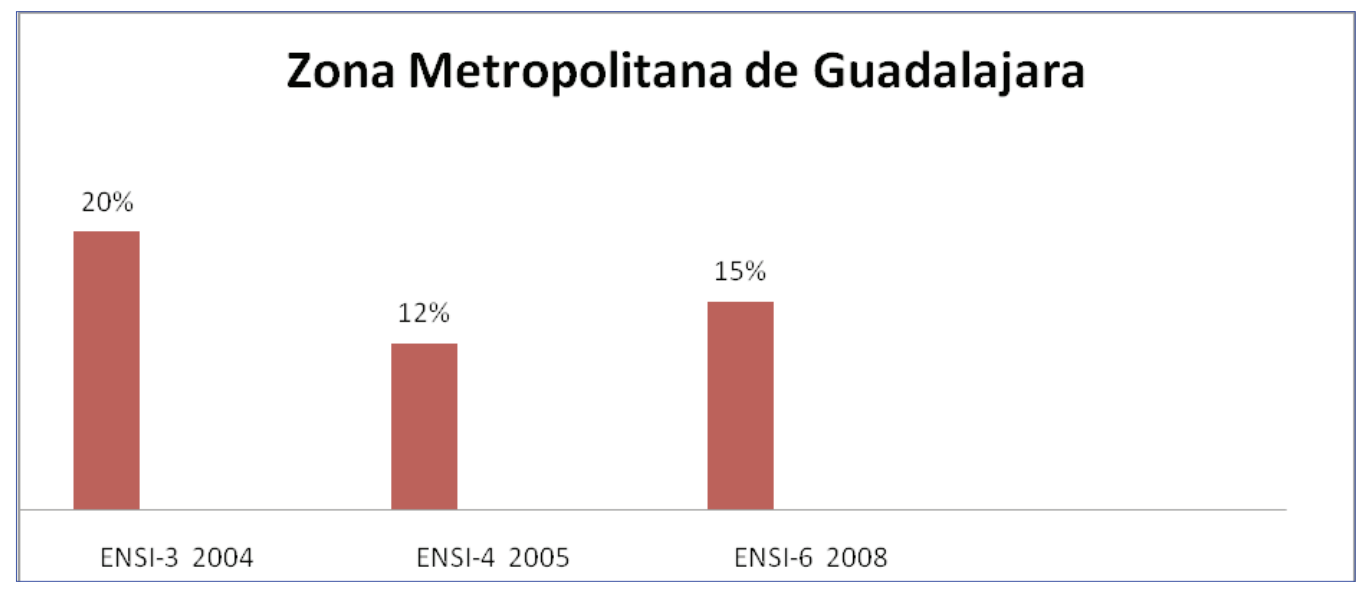

Gráfica 1 - Porcentaje de personas de 18 años o más víctimas en la República Mexicana en las ciudades de estudio.

Fuente: Sexta Encuesta Nacional sobre Inseguridad - Victimización urbana - Prevalencia; en, http://www. icesi.org.mx/documentos/encuestas/encuestasNacionales/ENSI6 urbana.pdf página 15.

\footnotetext{
${ }^{2}$ Consultar,http://cuentame.inegi.gob.mx/monografias/informacion/jal/poblacion/default. aspx?tema $=$ me\&e $=14$

${ }^{3}$ Revisar;http://cuentame.inegi.gob.mx/monografias/informacion/jal/poblacion/distribucion. aspx?tema $=$ me\&e=14 y http://cuentame.inegi.gob.mx/monografias/informacion/jal/poblacion/default. aspx? tema $=$ me\&e $=14$

4 Ver; http://coepo.jalisco.gob.mx/index.html; http://coepo.jalisco.gob.mx/html/I zonametropolitanagdl. html y, COEPO, "Análisis Sociodemográfico para la Zona Metropolitana de Guadalajara", marzo de 2008, página 7; en, http://coepo.jalisco.gob.mx/PDF/Analisissociodemograficos/Zmg.pdf
} 
Se trata de los resultados de las Encuestas Nacionales sobre Inseguridad (ENSI), que incluye 14 zonas urbanas metropolitanas (16 a partir de 2008), entre ellas la Zona metropolitana de Guadalajara (ZMG).

El porcentaje de personas de 18 años o más víctimas de un delito en la ZMG sufre un incremento, al pasar de $12 \%$ a $15 \%$, de 2005 a 2008 ; pero, todavía se encuentra por debajo del $20 \%$ arrojado en los resultados de $2004 .^{5}$

No obstante, en la ZMG se verifica un aumento de personas de 18 años o más que reconocen haber sido víctimas de un delito en los últimos tres años en su ciudad, tal como puede apreciarse en la siguiente tabla:

Tabla 1 - Porcentaje de Personas de 18 años o más víctimas en SU CiUdad, de las 14 zonas urbanas de estudio de la República Mexicana

\begin{tabular}{|c|c|c|}
\hline CIUDAD & ENSI-4/05 \% & ENSI-6/08\% \\
\hline Chihuahua & 9 & 19 \\
\hline DF & 27 & 19 \\
\hline Mexicali & 17 & 18 \\
\hline Ciudad de México & 21 & 18 \\
\hline ZCMex & 15 & 17 \\
\hline Tijuana & 17 & 16 \\
\hline Ciudad Juárez & 12 & 15 \\
\hline Cancún & 13 & 14 \\
\hline Guadalajara & 11 & 14 \\
\hline Acapulco & 14 & 13 \\
\hline Cualiacán & 12 & 11 \\
\hline Oaxaca & 12 & 11 \\
\hline Monterrey & 9 & 10 \\
\hline Toluca & 12 & 10 \\
\hline Cuernavaca & 7 & 10 \\
\hline Global Ciudades & 16 & 16 \\
\hline
\end{tabular}

Ciudades con cambio estadístico significativo del 2005 al 2008 Subió

Bajó

Fuente: Sexta Encuesta Nacional sobre Inseguridad - Victimización urbana - Prevalencia; en, http://www.icesi. org.mx/documentos/encuestas/encuestasNacionales/ENSI6 urbana.pdf página 23, el subrayado es nuestro.

\footnotetext{
5 Ver; Sexta Encuesta Nacional sobre Inseguridad - Victimización urbana - Prevalencia; en, http://www.icesi.org.mx/ documentos/encuestas/encuestasNacionales/ENSI6 urbana.pdf página 16.
} 
Este reconocimiento guarda correspondencia con la tasa de delitos por 100,000 habitantes que, siguiendo la misma fuente, sufre un incremento de 2005 a 2008.

TABla 2 - TASA DE DELITOS POR 100 MIL habitANTES

\begin{tabular}{|c|c|c|c|}
\hline CIUDAD & ENSI-3/04 & ENSI-4/05 & ENSI-6/08 \\
\hline Distrito Federal & 19,700 & 32,600 & 22,800 \\
\hline Ciudad de México & 20,500 & 24,900 & 21,200 \\
\hline Chihuahua & 12,400 & 9,000 & 21,100 \\
\hline Mexicali & 22,200 & 19,100 & 21,000 \\
\hline ZCMex & NA & 18,000 & 19,700 \\
\hline Guadalajara & 21,200 & 10,600 & 18,300 \\
\hline Tijuana & 22,800 & 19,400 & 16,800 \\
\hline Cd. Juárez & 14,100 & 11,700 & 16,600 \\
\hline Toluca & & 11,600 & 16,200 \\
\hline Cancún & 14,800 & 12,900 & 16,000 \\
\hline Acapulco & 20,900 & 14,800 & 14,400 \\
\hline Monterrey & 8,000 & 8,600 & 14,200 \\
\hline Oaxaca & 13,200 & 12,400 & 13,900 \\
\hline Culiacán & 25,700 & 10,900 & 12,300 \\
\hline Cuernavaca & 14,400 & 7,900 & 11,700 \\
\hline $\begin{array}{l}\text { Global } \\
\text { Ciudades }\end{array}$ & 18,700 & 18,600 & 18,900 \\
\hline Nacional & 11,200 & NA & 12,000 \\
\hline
\end{tabular}

Fuente: Sexta Encuesta Nacional sobre Inseguridad - Victimización urbana - Incidencia; en, http://www.icesi. org.mx/documentos/encuestas/encuestasNacionales/ENSI6 urbana.pdf página 25, el subrayado es nuestro.

Una forma de estimar la violencia urbana es a través del porcentaje de delitos cometidos a mano armada que, en el caso de la ZMG, es bajo (14\%) si se lo compara con las otras metrópolis consideradas, con el global de las ciudades (32\%) y la media nacional (25\%).

TAbla 3 - Delitos a mano armada

\begin{tabular}{|c|c|}
\hline CIUDAD & \% Delitos a mano armada \\
\hline Acapulco & 49 \\
\hline
\end{tabular}




\begin{tabular}{|c|c|}
\hline ZCMex & 45 \\
\hline Ciudad de México & 41 \\
\hline DF & 37 \\
\hline Cuernavaca & 33 \\
\hline Culiacán & 31 \\
\hline Cancún & 26 \\
\hline Tijuana & 26 \\
\hline Cd. Juárez & 24 \\
\hline Toluca & 24 \\
\hline Oaxaca & 18 \\
\hline Mexicali & 14 \\
\hline Guadalajara & $\mathbf{1 4}$ \\
\hline Monterrey & 13 \\
\hline Chihuahua & 9 \\
\hline Global Ciudades & 32 \\
\hline Nacional & 25 \\
\hline
\end{tabular}

Fuente: Sexta Encuesta Nacional sobre Inseguridad - Victimización urbana; en, http://www.icesi.org.

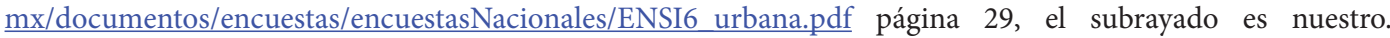

Sin embargo, en la ZMG, poco más de la mitad de la población (53\%) considera a su municipio inseguro.

Tabla 4 - Porcentaje de la población de 18 y más aÑos, en 16 zonas urbanas de la RePÚbliCa MEXICANA, QUE CONSIDERA SU MUNICIPIO INSEGURO

\begin{tabular}{|c|c|c|c|}
\hline CIUDAD & $\begin{array}{c}\text { ENSI-3/04 } \\
\%\end{array}$ & $\begin{array}{c}\text { ENSI-4/05 } \\
\%\end{array}$ & $\begin{array}{c}\text { ENSI-6/08 } \\
\%\end{array}$ \\
\hline Chihuahua & 42 & 42 & 82 \\
\hline Cd. Juárez & 80 & 76 & 82 \\
\hline Acapulco & 66 & 83 & 78 \\
\hline Culiacán & 81 & 73 & 77 \\
\hline Tijuana & 72 & 71 & 73 \\
\hline Cancún & 65 & 71 & 66 \\
\hline DF & 62 & 57 & \\
\hline
\end{tabular}




\begin{tabular}{|c|c|c|c|}
\hline Cd. De México & 61 & 59 & 66 \\
\hline ZCMex & & 61 & 65 \\
\hline Cuernavaca & 54 & 49 & 62 \\
\hline Toluca & & 51 & 59 \\
\hline Monterrey & 30 & 40 & 57 \\
\hline Oaxaca & 40 & 39 & 53 \\
\hline Mexicali & 47 & 59 & $\mathbf{5 3}$ \\
\hline Guadalajara & $\mathbf{5 0}$ & 57 & 65 \\
\hline Global Ciudades & 57 & NA & 49 \\
\hline Nacional & 40 & & \\
\hline
\end{tabular}

Fuente: Sexta Encuesta Nacional sobre Inseguridad - Victimización urbana - Inseguridad en el municipio; en, http://www.icesi.org.mx/documentos/encuestas/encuestasNacionales/ENSI6 urbana.pdf página 38, el subrayado es nuestro.

Tratándose de los resultados de las ENSI, a cargo del ICESI, la percepción de inseguridad en la ZMG en 2008 es de 53\%; aunque solo 14\% de la población mayor de edad reconoce haber sido víctima de un delito en su ciudad y el mismo porcentaje bajo la modalidad de "a mano armada".

3. SEGUNDA APROXIMACIÓN: SEGURIDAD SUBJETIVA DE ACUERDO CON LOS RESULTADOS DEL PROYECTO JUSTICIABARÓMETRO 2009.

Se refiere al cuestionario dirigido a los efectivos de la policía preventiva de los municipios de la ZMG: El Salto, Guadalajara, Tlaquepaque, Tlajomulco de Zúñiga, Tonalá, y Zapopan, y cuyos principales resultados de presentan a continuación.

Así, de acuerdo con los funcionarios encargados de hacer cumplir la ley encuadrados en la Dirección General de Seguridad Pública de Guadalajara (DGSPG) que participaron en la encuesta, los problemas que se presentan con mayor frecuencia en materia de seguridad pública son el robo de automóvil, el pandillerismo, el robo a casa-habitación y el tráfico de drogas. 


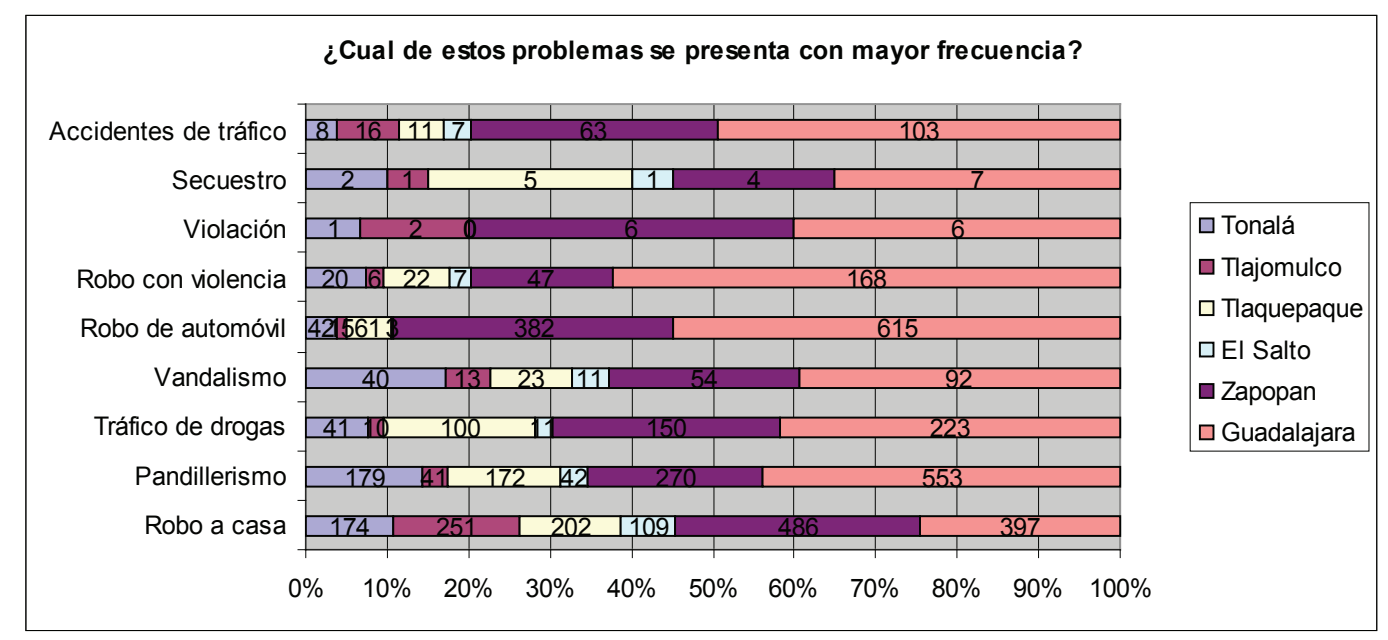

Gráfica 2 - Problemas que se presentan con mayor frecuencia

Fuente: Universidad de San Diego/Universidad de Guadalajara/ITESO, Proyecto Justiciabarómetro, 2009.

En tanto que, para los propios uniformados, los delitos más difíciles de resolución son el secuestro, el tráfico de drogas y el robo de automóvil.

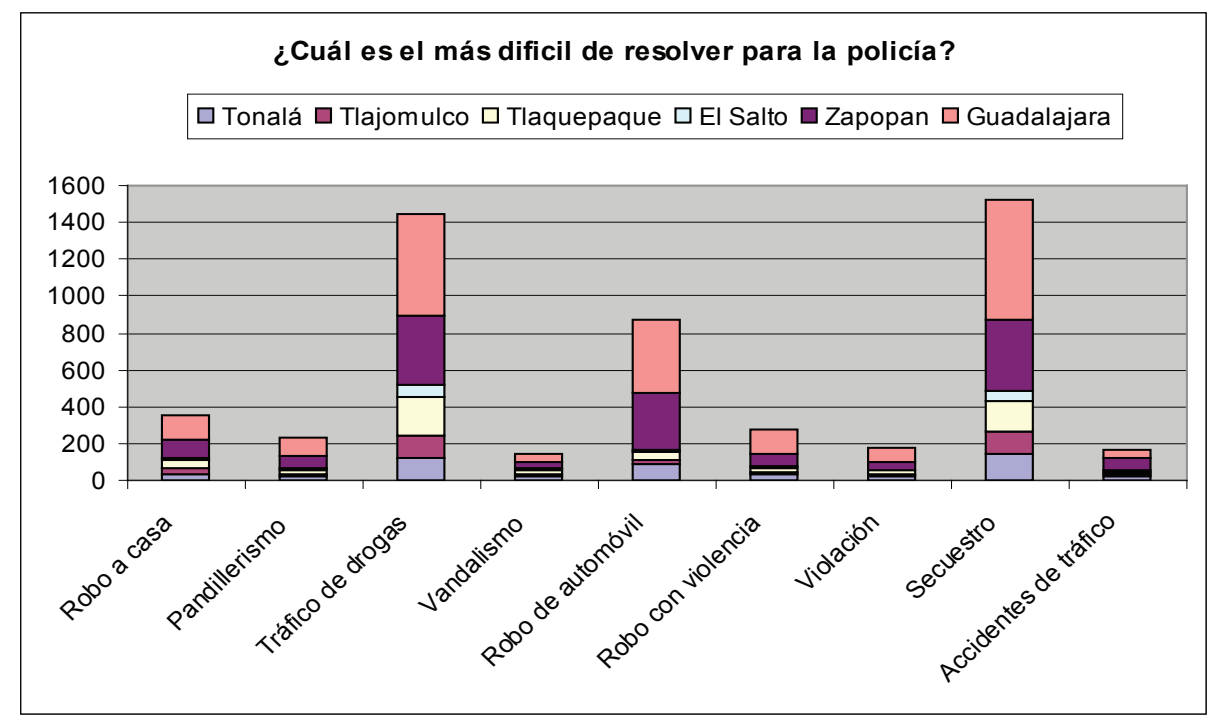

Gráfica 3 - Delitos más difíciles de resolver para la policía

Fuente: Universidad de San Diego/Universidad de Guadalajara/ITESO, Proyecto Justiciabarómetro, 2009. 


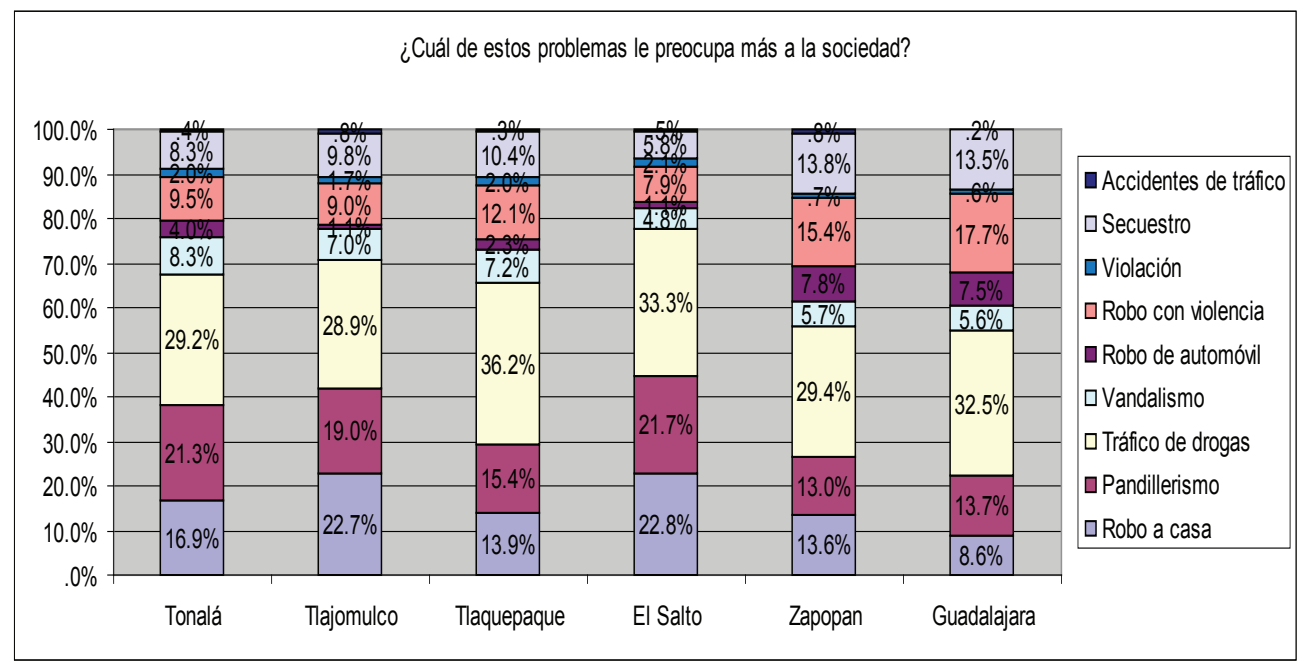

Gráfica 4 - Problema que más le preocupa a la sociedad en el ámbito de la seguridad

Fuente: Universidad de San Diego/Universidad de Guadalajara/ITESO, Proyecto Justiciabarómetro, 2009.

Mientras que, en el imaginario policial, los problemas que más le preocupan a la sociedad en el ámbito de la seguridad ciudadana en el municipio de Guadalajara, son el tráfico de drogas y el robo con violencia; $y$, en menor medida, el pandillerismo y el secuestro.

A la luz de lo cual, reconocen que la acción más eficiente para poner fin a la inseguridad dominante es apostar por una mayor participación de la comunidad.

En síntesis, en opinión de los propios policías preventivos de Guadalajara, los delitos patrimoniales (robo vehículos, robo de casa-habitación y robo con violencia), el accionar de las pandillas y el tráfico de drogas, se presentan como los principales problemas de inseguridad; siendo el robo con violencia y el tráfico de drogas los que más le preocupan a la sociedad.

\section{TERCERA APROXIMACIÓN: SEGURIDAD SUBJETIVA DE CONFORMIDAD CON EL ESTUDIO} CUALITATIVO RADIOGRAFÍA CIUDADANA DE GUADALAJARA

A partir de los resultados del trabajo de campo desarrollado en el marco del estudio cualitativo Radiografía Ciudadana de Guadalajara, es posible identificar y agrupar las colonias y barrios más inseguros y más seguros de Guadalajara; intentándose verificar si existe una correlación relativa entre la calidad de los servicios municipales y la percepción de seguridad/ inseguridad de los ciudadanos, tal como se establece en la introducción.

En este marco, la seguridad subjetiva, es decir, el sentimiento de seguridad/inseguridad de la población, se puede clasificar mediante las siguientes categorías consideradas:

Verde, cuyo significado es una percepción de la seguridad satisfactoria; los vecinos se sienten seguros y se quejan menos con respecto a sus pares de otros espacios del municipio.

Amarillo, los ciudadanos opinan que la situación de su seguridad es poco satisfactoria, con problemas moderados; los residentes se quejan, pero aceptan no estar tan inseguros en comparación con otras colonias y barrios. 
Rojo, escenario signado por una percepción generalizada de inseguridad e intranquilidad, que se traduce en indefensión ciudadana y miedo, incluso, a salir a la calle de día; el ciudadano se suele quejar de manera reiterada y siente que los problemas lo rebasan.

En lo que respecta a los servicios públicos municipales, a los efectos de este trabajo, se consideran -por guardar una íntima relación con el sentimiento ciudadano de seguridad/ inseguridad- la luz (incluyendo el alumbrado público y la electricidad en los hogares), agua y calles, principalmente.

En cuanto a la calidad de estos servicios públicos prestados por el municipio, se pueden distinguir los siguientes:

Verde, son los percibidos como buenos u óptimos servicios.

Amarillo: servicios considerados regulares, con riesgo de sufrir un proceso de deterioro, de no tomarse medidas correctivas a tiempo.

Rojo: servicios malos, pésimos o insuficientes.

Ahora bien, de llevarse a cabo un balance de la seguridad subjetiva en relación con la calidad de los servicios prestados por el ayuntamiento de Guadalajara, llama la atención que:

- aproximadamente la cuarta parte de la población se sienta segura (verde): $17 \%$ de buenos servicios y percepción de seguridad satisfactoria, al que se suma $6 \%$ de servicios regulares y percepción de seguridad satisfactoria.

- 20\% de los ciudadanos reconozcan una situación de inseguridad y temor (rojo), de la mano de: malos servicios (3\%), servicios de calidad regular (8\%) e, incluso, buenos servi$\operatorname{cios}(10 \%)$.

- poco más de la mitad (56\%) de los vecinos aceptan tener una percepción de seguridad poco satisfactoria, con problemas moderados (amarillo); lo que debería ser un toque de atención para las autoridades municipales, ya que significa una situación de alerta que podría deteriorarse y derivar en indefensión social (rojo), de no adoptarse ex ante políticas, estrategias y líneas de acción.

Por su parte, la Dirección General de Seguridad Pública de Guadalajara (DGSPG) divide al municipio en nueve zonas, en las que se encuentra desplegado un total de 3,362 efectivos policiales, para dar cobertura a una población de 1,600,940 habitantes que viven en una superficie de $187.91 \mathrm{~km} 2 .^{6}$

Para efectos operativos, cada zona y agrupamiento cuenta con su cuartel y mandos específicos; y es a partir de esta zonificación, que se intenta integrar a los barrios, unidades habitacionales y colonias de Guadalajara, y se presenta la situación de los servicios y seguridad desde la perspectiva ciudadana.

\footnotetext{
6 INEGI; en, http://www.inegi.gob.mx (población fija). COEPO, Vid Supra. Comisión Estratégica de Seguridad Pública y Sistema Estatal de Información sobre Seguridad Pública, Guadalajara, diciembre 2008.
} 


\section{Gráfica 6 - Relación servicios-seguridad Guadalajara}

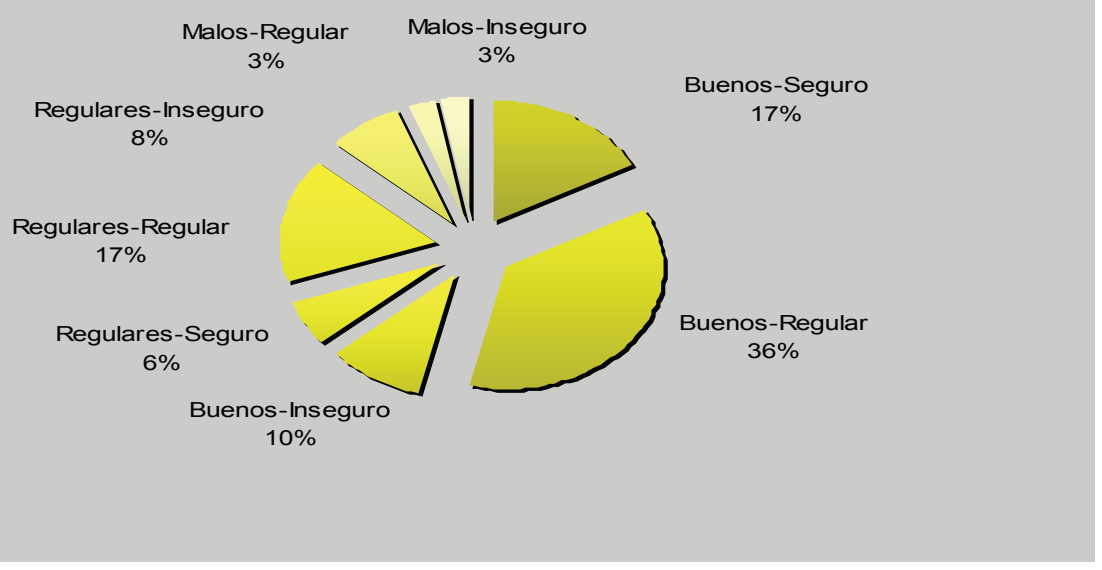

Fuente: elaboración propia, con base en; Radiografía Ciudadana de Guadalajara, estudio cualitativo 2007-2008.

\section{Mapa 1 - Zonas de Guadalajara, De CONFORMidad con la DGSPG}

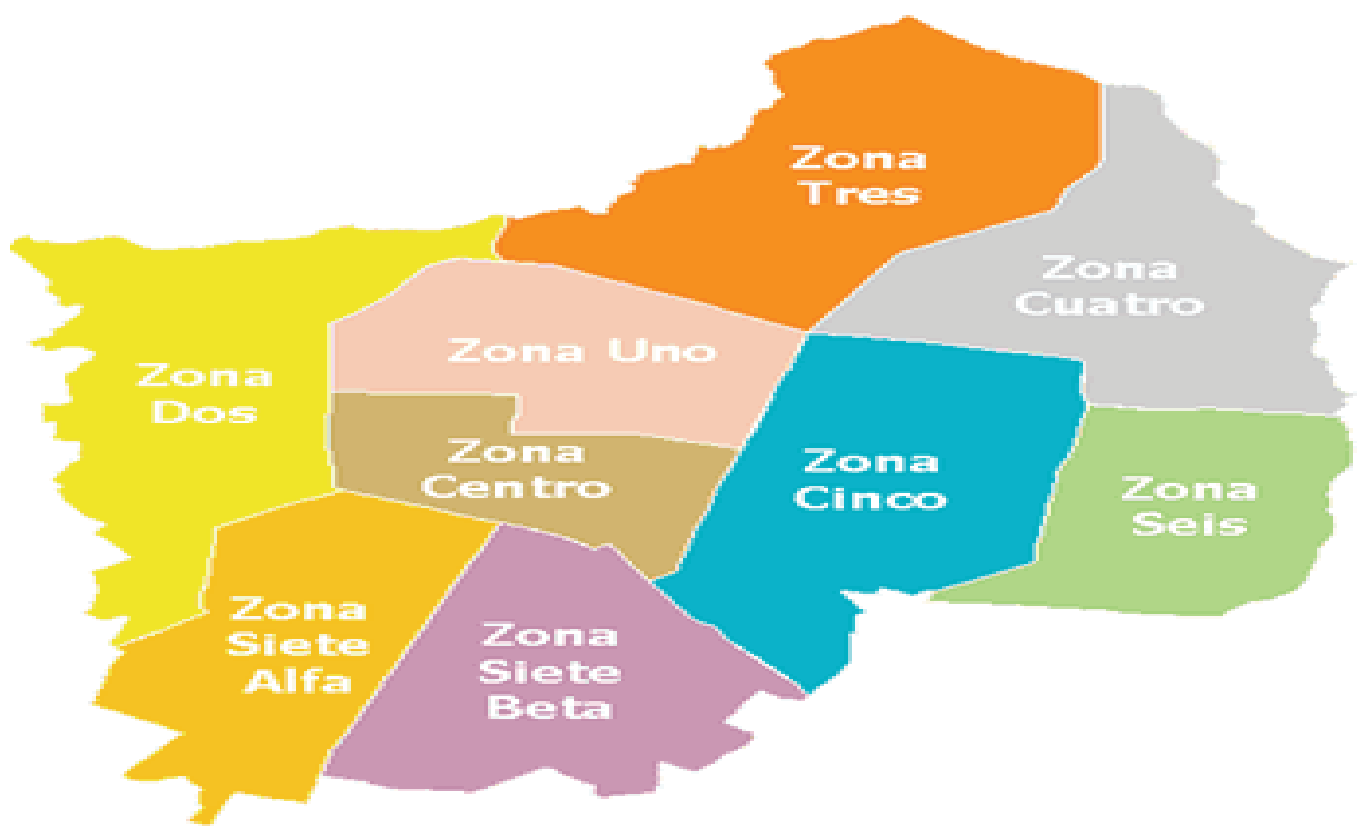

Fuente: Agrupamientos de la Policía Municipal Preventiva de Guadalajara, DGSPG; en, http://www.Guadalajara.gob.mx/seguridadpublica/zonas-agrupamientos.htm 
La zona Centro se caracteriza por agrupar a San Bernardo, Barrio de Mezquitán, Alcalde Barranquitas, Colinas de la Normal, Santa Elena Poniente y Oriente, y Capilla de Jesús, como colonias cuyos vecinos perciben inseguras (rojo). En contraste, en Niños Héroes y San Miguel de Mezquitán, El Retiro, Colonia Americana y Country Tercera Sección, los colonos se sienten seguros (verde). Aunque en la mayoría de los espacios que integran la zona Centro, los ciudadanos tienen una percepción de seguridad poco satisfactoria (amarillo).

No obstante, en las estadísticas oficiales esta zona -particularmente, sus colonias Centro, Mezquitán Country, El Retiro y El Santuario- encabeza el robo a casa-habitación y a vehículos en 2007, homicidios dolosos durante 2008, y el robo a personas, a negocios y a vehículos particulares, a lo largo de ambos años; así como las detenciones por la comisión de faltas administrativas y delitos del fuero común y del fuero federal. ${ }^{7}$

Cabe destacar que esta zona es una de las que puede jactarse de contar con los mejores servicios públicos municipales de Guadalajara, al presentar la mayor satisfacción ciudadana (verde), tal como se desprende de la consulta pública.

Tabla 5 - Zona Centro (Zona Centro de la DGSPG)

\begin{tabular}{|c|c|c|c|}
\hline Seguridad & Servicios & Colonia & Trabajo de Campo \\
\hline Verde & Verde & $\begin{array}{l}\text { Niños Héroes y San Miguel de Mezqui- } \\
\text { tán }\end{array}$ & - - - - - - - - \\
\hline Rojo & Verde & San Bernardo y Barrio de Mezquitán & $\begin{array}{l}\text { Mezquitán / Chapulte- } \\
\text { pec Country }\end{array}$ \\
\hline Rojo & Amarillo & $\begin{array}{l}\text { Alcalde Barranquitas y Colinas de la } \\
\text { Normal }\left({ }^{*}\right)\end{array}$ & Barranquitas \\
\hline Amarillo & Verde & Villas de San Juan e Independencia & Barranquitas \\
\hline Amarillo & Verde & $\begin{array}{l}\text { Unidad Habitacional Miguel Galindo } \\
\text { y Unidad Habitacional Fray Antonio } \\
\text { Alcalde }\end{array}$ & Chapultepec Country \\
\hline Amarillo & Verde & Mezquitán / Mezquitán Country & Mezquitán \\
\hline Amarillo & Amarillo & $\begin{array}{l}\text { La Normal / Unidad Habitacional Ra- } \\
\text { món Corona }\end{array}$ & Mezquitán \\
\hline Rojo & Rojo & Santa Elena Poniente y Oriente & $\begin{array}{l}\text { Huentitán / Santa Elena } \\
\text { / Santa Elena Alcalde }\end{array}$ \\
\hline Rojo & Verde & Capilla de Jesús & Belén \\
\hline Verde & Verde & El Retiro & Belén \\
\hline Amarillo & Amarillo & El Santuario Primera Sección & Belén \\
\hline Amarillo & Verde & Mexicalzingo & Mexicalzingo \\
\hline
\end{tabular}

\footnotetext{
7 Delitos de impacto social 2007 y 2008; estadísticas proporcionadas por la Dirección Técnica dependiente de la DGSPG, con base en la Procuraduría General de Justicia del Estado de Jalisco.
} 


\begin{tabular}{|l|l|l|l|}
\hline Amarillo & Verde & Colonia Centro & Mexicalzingo \\
\hline Verde & Verde & Colonia Americana & Mexicalzingo \\
\hline Amarillo & Verde & Chapultepec Country & Chapultepec Country \\
\hline Verde & Verde & Country Tercera Sección & Chapultepec Country \\
\hline Amarillo & Verde & $\begin{array}{l}\text { Independencia Sur e Independencia } \\
\text { Oriente }\end{array}$ & Independencia \\
\hline Amarillo & Amarillo & Ayuntamiento y Villaseñor & Mezquitán \\
\hline
\end{tabular}

${ }^{*}$ ) La comunidad universitaria puede corroborar la inseguridad que caracteriza a ambas colonias, debido al elevado número de testimonios de víctimas de delitos pertenecientes al Centro Universitario de Ciencias Sociales y Humanidades (CUCSH) de la Universidad de Guadalajara.

Fuente: elaboración propia, con base en; Radiografía Ciudadana de Guadalajara, estudio cualitativo 2007-2008.

La zona Minerva es relativamente segura, dado que solo presenta focos rojos en las Unidades Habitacionales Miguel Galindo y Fray Antonio Alcalde, Rinconada del Bosque e Hípico Tapatío (rojo); siendo colonias percibidas como seguras Rojas Ladrón de Guevara y Barrera, Providencia Segunda, Tercera y Cuarta Sección, Rinconada de Santa Rita y Monraz, Jardines del Bosque Norte, Vallarta Sur, Colinas de San Javier, Villas de los Colomos, Lomas del Country, Rinconada del Arroyo, Italia e Italia Providencia (verde). Sin embargo, al igual que la zona Centro, la mayoría de los vecinos no se encuentran satisfechos en materia de seguridad ciudadana (amarillo); lo que se ve confirmado al consultarse los datos oficiales que dan cuenta del robo a casa-habitación como uno de los principales delitos cometidos durante 2007 y a vehículos en 2007 y 2008 en Italia Providencia. ${ }^{8}$

Al igual que la zona Centro, la zona Minerva se caracteriza por un elevado grado de satisfacción en lo que a prestación de servicios públicos municipales se refiere (verde).

Tabla 6 - Zona Minerva (Zonas 1 y 2 DE La DGSPG)

\begin{tabular}{|c|c|c|c|}
\hline Seguridad & Servicios & Colonia & Trabajo de Campo \\
\hline Amarillo & Amarillo & $\begin{array}{l}\text { Arcos Vallarta Primera y Segunda Sección } \\
\text { y Arcos Sur }\end{array}$ & Arcos Vallarta \\
\hline Verde & Verde & Rojas Ladrón de Guevara y Barrera & Arcos Vallarta \\
\hline Rojo & Verde & $\begin{array}{l}\text { Unidad Habitacional Miguel Galindo y } \\
\text { Unidad Habitacional Fray Antonio Alcalde }\end{array}$ & $\begin{array}{l}\text { Chapultepec Coun- } \\
\text { try }\end{array}$ \\
\hline Verde & Amarillo & $\begin{array}{l}\text { Providencia Segunda, Tercera y Cuarta } \\
\text { Sección }\end{array}$ & $\begin{array}{l}-\cdots-\cdots-1 \\
-\cdots\end{array}$ \\
\hline Amarillo & Verde & Verde Valle y Bosques de la Victoria & $\begin{array}{l}\text { Bosques de la Vic- } \\
\text { toria }\end{array}$ \\
\hline Verde & Verde & Rinconada de Santa Rita y Monraz & Monraz \\
\hline
\end{tabular}

8 Ibidem. 


\begin{tabular}{|c|c|c|c|}
\hline Amarillo & Amarillo & $\begin{array}{l}\text { Residencial Juan Manuel y Fraccionamien- } \\
\text { to Terranova }\end{array}$ & Providencia Sur \\
\hline Amarillo & Verde & Jardines del Bosque Norte / Vallarta Sur & Jardines del Bosque \\
\hline Amarillo & Verde & $\begin{array}{l}\text { Arcos Sur/ Arcos Vallarta Primera y Se- } \\
\text { gunda Sección }\end{array}$ & Arcos Vallarta \\
\hline Amarillo & Amarillo & Colomos Providencia & Colomos Providencia \\
\hline Amarillo & Verde & Providencia / Providencia Quinta Sección & $\begin{array}{l}\text { Colomos Providen- } \\
\text { cia / Providencia }\end{array}$ \\
\hline Amarillo & Verde & $\begin{array}{l}\text { Circunvalación Vallarta / Circunvalación } \\
\text { Guevara }\end{array}$ & Providencia Sur \\
\hline Amarillo & Verde & $\begin{array}{l}\text { Residencial Juan Manuel / Fraccionamien- } \\
\text { to Terranova }\end{array}$ & Providencia Sur \\
\hline Amarillo & Verde & $\begin{array}{l}\text { Prados Providencia / Circunvalación Sar- } \\
\text { cófago }\end{array}$ & Providencia \\
\hline Amarillo & Verde & Terrazas Monraz & Monraz \\
\hline Verde & Verde & Jardines del Bosque Norte / Vallarta Sur & Jardines del Bosque \\
\hline Amarillo & Verde & $\begin{array}{l}\text { Arcos Sur / Arcos Vallarta Primera y Se- } \\
\text { gunda Sección }\end{array}$ & Arcos Vallarta \\
\hline Amarillo & Amarillo & $\begin{array}{l}\text { Prados Providencia / Circunvalación Sar- } \\
\text { cófago }\end{array}$ & Providencia \\
\hline Amarillo & Verde & Terrazas Monraz & Monraz \\
\hline Amarillo & Amarillo & Agraria y Aldrete & Colomos Providencia \\
\hline Amarillo & Amarillo & Colomos y Colomos Providencia & Colomos Providencia \\
\hline Amarillo & Verde & Verde Valle y Bosques de la Victoria & $\begin{array}{l}\text { Bosques de la Vic- } \\
\text { toria }\end{array}$ \\
\hline Verde & Verde & $\begin{array}{l}\text { Colinas de San Javier y Villas de los Colo- } \\
\text { mos }\end{array}$ & Colinas de San Javier \\
\hline Amarillo & Verde & Ladrón de Guevara & Ladrón de Guevara \\
\hline Amarillo & Rojo & Lomas de Guevara & Providencia Sur \\
\hline Amarillo & Verde & Lomas de Providencia y Lomas del Valle & $\begin{array}{l}\text { Providencia Norte y } \\
\text { Monraz }\end{array}$ \\
\hline Verde & Amarillo & Lomas del Country & Country Club \\
\hline Amarillo & Amarillo & Vallarta Poniente & Vallarta San Jorge \\
\hline Rojo & Amarillo & Rinconada del Bosque e HípicoTapatío & $\begin{array}{l}\text { Bosques de la Vic- } \\
\text { toria }\end{array}$ \\
\hline
\end{tabular}




\begin{tabular}{|l|l|l|l|}
\hline Amarillo & Verde & $\begin{array}{l}\text { Jardines de Plaza del Sol y Chapalita Cam- } \\
\text { po de Polo }\end{array}$ & $\begin{array}{l}\text { Chapalita Campo de } \\
\text { Polo }\end{array}$ \\
\hline Verde & Verde & Rinconada del Arroyo & Colomos \\
\hline Verde & Verde & Italia e Italia Providencia & $\begin{array}{l}\text { Providencia Norte y } \\
\text { Providencia Sur }\end{array}$ \\
\hline Amarillo & Verde & $\begin{array}{l}\text { Jardines del Bosque Sección Centro, Norte } \\
\text { y vecindades }\end{array}$ & Jardines del Bosque \\
\hline
\end{tabular}

Fuente: elaboración propia, con base en; Radiografía Ciudadana de Guadalajara, estudio cualitativo 2007-2008.

La zona Oblatos, junto con Cruz del Sur, son -siguiendo la percepción ciudadana- las más inseguras de Guadalajara; lo que se ve confirmado con el robo a personas y a negocios, así como por el elevado número de detenciones por faltas administrativas y la presunta comisión de delitos del fuero común y federal, al consultarse las estadísticas oficiales. ${ }^{9}$

En el caso de aquella, las colonias, unidades habitacionales y barrios Beatriz Hernández, San Marcos Oriente y Poniente, Circunvalación Belisario, San Miguel de Huentitán Tercera Sección, Rinconada de Huentitán, Guadalajara Oriente, Margarita Maza de Juárez, San José Río Verde Primera y Segunda Sección, Bethel, Oblatos Segunda Sección, Unidad Habitacional Río Verde Oblatos, Unidad Habitacional Tetlán Río Verde, Balcones de Oblatos Primera y Segunda Sección, Jardines de la Barranca y El Zalate, son a todas luces las de mayor inseguridad (rojo); presentándose tan solo la colonia Oblatos Anexo como segura (verde).

Tratándose de la calidad de los servicios públicos, se presenta una situación de empate entre los ciudadanos que los consideran satisfactorios (verde) y los que los perciben como regulares o poco satisfactorios (amarillo).

Tabla 7 - Zona Oblatos (Zona 4 DE la DGSPG)

\begin{tabular}{|l|l|l|l|}
\hline \multicolumn{1}{|c|}{ Seguridad } & Servicios & \multicolumn{1}{|c|}{ Colonia } & \multicolumn{1}{|c|}{ Trabajo de Campo } \\
\hline Rojo & Amarillo & Beatriz Hernández & Lomas de Oblatos \\
\hline Rojo & Verde & $\begin{array}{l}\text { San Marcos Oriente y Poniente y } \\
\text { Circunvalación Belisario }\end{array}$ & San Marcos Oriente \\
\hline Amarillo & Verde & $\begin{array}{l}\text { Huentitán el Alto y la Joyita de } \\
\text { Huentitán }\end{array}$ & La Joyita \\
\hline Rojo & Rojo & $\begin{array}{l}\text { San Miguel de Huentitán Tercera } \\
\text { Sección y Rinconada de Huentitán }\end{array}$ & La Joyita \\
\hline Amarillo & Verde & San Eugenio y Hacienda de Oblatos & Balcones de Oblatos \\
\hline Amarillo & Amarillo & Arandas y San Crispín & Arandas \\
\hline Amarillo & Verde & 5 de mayo Primera Sección & - - - - - - - - - - - \\
\hline Amarillo & Verde & Santa Rosa & $\begin{array}{l}\text { Calzada del Obrero de la } \\
\text { Huerta }\end{array}$ \\
\hline
\end{tabular}

9 Ibidem. 


\begin{tabular}{|c|c|c|c|}
\hline Rojo & Amarillo & $\begin{array}{l}\text { Guadalajara Oriente / Margarita } \\
\text { Maza de Juárez }\end{array}$ & $\begin{array}{l}\text { Calzada del Obrero de la } \\
\text { Huerta }\end{array}$ \\
\hline Verde & Amarillo & Oblatos Anexo & Calzada del Obrero de la \\
\hline Rojo & Rojo & $\begin{array}{l}\text { San José Río Verde Primera y Se- } \\
\text { gunda Sección }\end{array}$ & Heliodoro Hernández Loza \\
\hline Rojo & Verde & Bethel & Heliodoro Hernández Loza \\
\hline Rojo & Amarillo & $\begin{array}{l}\text { Oblatos Segunda Sección, Unidad } \\
\text { Habitacional Río Verde Oblatos, } \\
\text { Unidad Habitacional Tetlán Río } \\
\text { Verde }\end{array}$ & Arandas \\
\hline Rojo & Verde & $\begin{array}{l}\text { Balcones de Oblatos Primera y Se- } \\
\text { gunda Sección }\end{array}$ & Balcones de Oblatos \\
\hline Rojo & Amarillo & Jardines de La Barranca & Jardines de La Barranca \\
\hline Amarillo & Verde & $\begin{array}{l}\text { Belisario Domínguez y Monumen- } \\
\text { tal }\end{array}$ & Monumental \\
\hline Rojo & Amarillo & El Zalate & El Zalate \\
\hline Amarillo & Amarillo & $\begin{array}{l}\text { La Joya y San Miguel de Huentitán } \\
\text { Segunda Sección }\end{array}$ & El Panteón \\
\hline
\end{tabular}

Fuente: elaboración propia, con base en; Radiografía Ciudadana de Guadalajara, estudio cualitativo 2007-2008.

La zona Huentitán se caracteriza por tener el mayor número de colonias, barrios y unidades habitacionales consideradas seguras (verde), a saber: Unidad Habitacional Simón Bolívar Santa Elena Alcalde, Dr. Atl y Villas de la Barranca, Josefina López de Isaac, Rancho San Antonio, Panorámica de Huentitán Segunda Sección, Unidad Habitacional Fidel Velásquez, Lomas del Paraíso Primera Sección, Guadalupana Norte, Circunvalación Metro, Jardines de Santa Isabel, Batallón San Patricio y Unidad Habitacional Estadio. En tanto Estadio Poniente, Jardines Alcalde, Huentitán el Bajo Primera y Segunda Sección y Panorámica de Huentitán, Primera Sección, son percibidas como altamente inseguras (rojo).

Sin embargo, a lo largo de 2007, San Antonio presentó el mayor número de homicidios dolosos y ocupó el segundo lugar en robo a vehículo de carga liviana en Guadalajara, siguiendo la información proporcionada por la DGSPG. ${ }^{10}$

Esta zona es la que, por lejos, cuenta -al decir de los propios vecinos- con los servicios de más calidad de Guadalajara (verde); siendo muy pocas las colonias en las que se perciben como regulares o poco satisfactorios (amarillo), y solo en Huentitán el Bajo Primera y Segunda Sección se consideran malos (rojo).

\footnotetext{
${ }^{10} 6$ y 4 casos, respectivamente; Vid Supra, Delitos de impacto social 2007; estadísticas proporcionadas por la Dirección Técnica dependiente de la DGSPG, con base en la Procuraduría General de Justicia del Estado de Jalisco. 
Tabla 8 - Zona Huentitán (Zona 3 DE La DGSPG)

\begin{tabular}{|c|c|c|c|}
\hline Seguridad & Servicios & Colonia & Trabajo de Campo \\
\hline Verde & Verde & $\begin{array}{l}\text { Unidad Habitacional Simón Bo- } \\
\text { lívar Santa Elena Alcalde }\end{array}$ & - - - - - - - - - \\
\hline Amarillo & Amarillo & Santa Elena Poniente y Oriente & Santa Elena Alcalde \\
\hline Verde & Verde & Dr. Atl y Villas de la Barranca & Zoológico \\
\hline Amarillo & Verde & $\begin{array}{l}\text { Villas de San Juan / Residencial } \\
\text { San Elías }\end{array}$ & Rancho Nuevo \\
\hline Amarillo & Verde & $\begin{array}{l}\text { Estado Poniente y Jardines Al- } \\
\text { calde }\end{array}$ & Santa Elena Alcalde \\
\hline Amarillo & Verde & $\begin{array}{l}\text { Guadalajara Oriente / Margarita } \\
\text { Maza de Juárez }\end{array}$ & Panteón \\
\hline Amarillo & Verde & $\begin{array}{l}\text { Villas de San Juan / Residencial } \\
\text { San Elías }\end{array}$ & Rancho Nuevo \\
\hline Rojo & Verde & $\begin{array}{l}\text { Estadio Poniente y Jardines Al- } \\
\text { calde }\end{array}$ & Santa Elena Alcalde \\
\hline Amarillo & Verde & $\begin{array}{l}\text { Guadalajara Oriente / Margarita } \\
\text { Maza de Juárez }\end{array}$ & Panteón \\
\hline Rojo & Rojo & $\begin{array}{l}\text { Huentitán el Bajo Primera y Se- } \\
\text { gunda Sección }\end{array}$ & Huentitán el Bajo \\
\hline$-\cdots$ & $\cdots \cdots-\cdots$ & Balcones de Huentitán & Huentitán el Bajo \\
\hline Verde & Verde & Josefina López de Isaac & Huentitán el Bajo \\
\hline Verde & Verde & Rancho San Antonio & Huentitán el Bajo \\
\hline Rojo & Verde & $\begin{array}{l}\text { Panorámica de Huentitán Prime- } \\
\text { ra Sección }\end{array}$ & Huentitán el Bajo \\
\hline Verde & Verde & $\begin{array}{l}\text { Panorámica de Huentitán Segun- } \\
\text { da Sección }\end{array}$ & Huentitán el Bajo \\
\hline Amarillo & Verde & $\begin{array}{l}\text { Santa Elena Estadio y Unidad } \\
\text { Habitacional Villas de San Juan }\end{array}$ & - \\
\hline Verde & Verde & $\begin{array}{l}\text { Unidad Habitacional Fidel Ve- } \\
\text { lázquez }\end{array}$ & 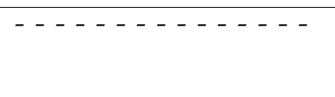 \\
\hline Amarillo & Verde & $\begin{array}{l}\text { La Cantera y Villas de la Cante- } \\
\text { rilla }\end{array}$ & Ricardo Flores Magón \\
\hline Amarillo & Verde & $\begin{array}{l}\text { Huentitán el Alto y Colinas de } \\
\text { Huentitán }\end{array}$ & Huentitán el Alto \\
\hline Verde & Verde & $\begin{array}{l}\text { Lomas del Paraíso Primera Sec- } \\
\text { ción }\end{array}$ & Lomas del Paraíso \\
\hline
\end{tabular}




\begin{tabular}{|l|l|l|l|}
\hline Verde & Verde & Guadalupana Norte & Santa Elena Alcalde \\
\hline Verde & Verde & Circunvalación Metro & Santa Elena Alcalde \\
\hline Amarillo & Verde & Estadio Poniente & Independencia \\
\hline Verde & Verde & Jardines de Santa Isabel & Ricardo Flores Magón \\
\hline Verde & Amarillo & $\begin{array}{l}\text { Batallón San Patricio y Unidad } \\
\text { Habitacional Estadio }\end{array}$ & Ricardo Flores Magón \\
\hline
\end{tabular}

Fuente: elaboración propia, con base en; Radiografía Ciudadana de Guadalajara, estudio cualitativo 2007-2008.

En la zona El Dean / La Nogalera los colonos consideran seguras (verde) las colonias Residencial de la Cruz y Jardines del Sur; mientras que en el resto la situación de la seguridad ciudadana se presenta poco satisfactoria (amarillo). En lo que respecta a los servicios, la situación es balanceada entre los que los perciben como buenos o satisfactorios (verde) y los que opinan que son de regular calidad (amarillo).

Tabla 9 - Zona El Dean / La Nogalera (Zonas 7 Alfa y Beta de la DGSPG)

\begin{tabular}{|l|l|l|l|}
\hline \multicolumn{1}{|c|}{ Seguridad } & Servicios & \multicolumn{1}{|c|}{ Colonia } & \multicolumn{1}{|c|}{ Trabajo de Campo } \\
\hline Verde & Verde & $\begin{array}{l}\text { Residencial de la Cruz y Jardines } \\
\text { del Sur }\end{array}$ & Jardines de la Cruz \\
\hline Amarillo & Amarillo & $\begin{array}{l}\text { Conjunto Habitacional Industria y } \\
\text { Blanco y Cuellar Segunda Sección }\end{array}$ & - - - - - - - - - - \\
\hline Amarillo & Verde & Unidad Valentín Gómez Farías & - - - - - - - - - - \\
\hline Amarillo & Amarillo & Obrera y Unidad Modelo & $-\ldots-\ldots-\ldots-\ldots-\ldots$ \\
\hline
\end{tabular}

Fuente: elaboración propia, con base en; Radiografía Ciudadana de Guadalajara, estudio cualitativo 2007-2008.

En el imaginario colectivo, tal como se adelantó, la zona Cruz del Sur se presenta como una de las de mayor inseguridad; siendo, en especial, Villa Vicente Guerrero, CROC (también conocida como residencial Jardines de San José), Miravalle Primera, Segunda, Tercera, Cuarta y Sexta Sección, $1^{\circ}$ de Mayo, 5 de Mayo Primera y Segunda Sección, Fraccionamiento Colón, Lomas de Polanco, 18 de Marzo y López Portillo, los barrios, colonias y unidades habitacionales considerados más inseguros (rojo). Pero, también incluye espacios percibidos como seguros (verde), tales como Industrial Segunda Sección, La Nogalera, El Manantial y Villa Hermosa, 8 de Julio / Tepopote, La Aurora, Abastos y Valle del Álamo.

Curiosamente, solo en el Fraccionamiento Colón y en la colonia Jardines de la Cruz Primera Sección, los residentes perciben servicios públicos de pésima calidad (rojo); puesto que, en el resto, la opinión es de regular (amarillo) a claramente favorable o aceptable (verde).

Tabla 10 - Zona Cruz del Sur (Zonas 7 Alfa y Beta de la DGSPG)

\begin{tabular}{|l|l|l|c|}
\hline Seguridad & Servicios & Colonia & Trabajo de Campo \\
\hline Verde & Amarillo & Industrial Segunda Sección & 5 de Mayo Rastro \\
\hline
\end{tabular}




\begin{tabular}{|c|c|c|c|}
\hline Amarillo & Amarillo & Tepopote Oeste y Morelos & Arboledas Abastos \\
\hline Verde & Amarillo & La Nogalera & El Dean - Nogalera \\
\hline Verde & Verde & El Manantial y Villa Hermosa & El Manantial \\
\hline Amarillo & Verde & Infonavit el Sauz y Jardines del & El Sauz \\
\hline Amarillo & Verde & $\begin{array}{l}\text { Sauz } \\
\text { Rinconada de la Arboleda y Frac- } \\
\text { cionamiento Las Torres }\end{array}$ & Arboledas Abasto \\
\hline Amarillo & Verde & Abastos & Arboledas Abasto \\
\hline Rojo & Verde & Villa Vicente Guerrero y CROC & Jardines del Sur \\
\hline Amarillo & Amarillo & Miravalle Secciones 8 y 9 & Miravalle \\
\hline Amarillo & Verde & $\begin{array}{l}\text { Jardines San José y Unidad Habita- } \\
\text { cional Colón }\end{array}$ & Jardines de la Cruz \\
\hline Rojo & Verde & $\begin{array}{l}\text { Villa Vicente Guerrero / CROC } \\
\text { (también conocida como residen- } \\
\text { cial Jardines de San José) }\end{array}$ & Jardines del Sur \\
\hline Amarillo & Verde & $\begin{array}{l}\text { Unidad Clemente Orozco/ Zona de } \\
\text { Industrias } 2\end{array}$ & Miravalle \\
\hline Amarillo & Verde & El Dean & El Dean-La Nogalera \\
\hline Rojo & Amarillo & $\begin{array}{l}\text { Villa Vicente Guerrero / CROC } \\
\text { (también conocida como residen- } \\
\text { cial Jardines de San José) }\end{array}$ & Jardines del Sur \\
\hline Amarillo & Amarillo & El Manantial & Miravalle \\
\hline Verde & Verde & 8 de Julio / Tepopote & 8 de Julio \\
\hline Verde & Verde & La Aurora & 8 de Julio \\
\hline Verde & Amarillo & La Nogalera & El Dean- Nogalera \\
\hline Amarillo & Verde & $\begin{array}{l}\text { Infonavit el Sauz y Jardines del } \\
\text { Sauz }\end{array}$ & El Sauz \\
\hline Amarillo & Amarillo & $\begin{array}{l}\text { Rinconada de la Arboleda y Frac- } \\
\text { cionamiento las Torres }\end{array}$ & Arboledas Abasto \\
\hline Verde & Amarillo & Abastos & Arboledas Abasto \\
\hline Rojo & Amarillo & Villa Vicente Guerrero y CROC & Jardines del Sur \\
\hline Amarillo & Amarillo & El Manantial y Villa Hermosa & El Manantial \\
\hline Amarillo & Amarillo & $\begin{array}{l}\text { Unidad Clemente Orozco / Zona } \\
\text { de Industrias } 2\end{array}$ & Miravalle \\
\hline Rojo & Verde & $\begin{array}{l}\text { Miravalle Segunda Sección y Mira- } \\
\text { valle Sexta Sección }\end{array}$ & Miravalle \\
\hline
\end{tabular}




\begin{tabular}{|l|l|l|l|}
\hline Rojo & Verde & $\begin{array}{l}\text { Primera Sección de Miravalle y }{ }^{\circ} \\
\text { de Mayo }\end{array}$ & Miravalle \\
\hline Rojo & Amarillo & $\begin{array}{l}\text { Miravalle Segunda Sección y Mira- } \\
\text { valle Sexta Sección }\end{array}$ & Miravalle \\
\hline Rojo & Amarillo & $\begin{array}{l}5 \text { de Mayo Primera y Segunda Sec- } \\
\text { ción }\end{array}$ & $\begin{array}{l}\text { Balcones del Cuatro y 5 de } \\
\text { Mayo Rastro }\end{array}$ \\
\hline Rojo & Rojo & Fraccionamiento Colón & Jardines de la Cruz \\
\hline Amarillo & Rojo & $\begin{array}{l}\text { Jardines de la Cruz Primera Sec- } \\
\text { ción }\end{array}$ & Jardines de la Cruz \\
\hline Amarillo & Verde & Villas del Jardín & Jardines de la Cruz \\
\hline Rojo & Verde & Miravalle Tercera y Cuarta Sección & Miravalle \\
\hline Verde & Amarillo & Valle del Álamo & Valle del Álamo \\
\hline Amarillo & Verde & El Fresno & Cruz del Sur \\
\hline Rojo & Amarillo & $\begin{array}{l}\text { Lomas de Polanco, 18 de Marzo y } \\
\text { López Portillo }\end{array}$ & Lomas de Polanco \\
\hline
\end{tabular}

Fuente: elaboración propia, con base en; Radiografía Ciudadana de Guadalajara, estudio cualitativo 2007-2008.

En la zona Tetlán, las colonias y unidades habitacionales en las que los ciudadanos se sienten más inseguros (rojo) son San Rafael, Residencial San Rafael, Unidad Habitacional los Arrayanes, Ramón López Velarde, San Francisco, Jardines San Francisco, Hermosa Provincia y Villas del Nilo. A excepción de Jardín de los Poetas, Unidad Habitacional San Rafael, Jardín de los Escritores y Jardín de los Historiadores, consideradas seguras (verde), la abrumadora mayoría de las colonias son percibidas como poco satisfactorias en materia de seguridad ciudadana por los residentes (amarillo).

Como en el caso anterior (zona Cruz del Sur), los vecinos opinan que solo en Unidad habitacional San Rafael, y en las colonias Jardín de los Poetas y Poblado de Tetlán, los servicios públicos municipales son prestados de manera deficiente (rojo); de manera tal que, en la mayor parte de la zona Tetlán los servicios se perciben como regulares (amarillos) y satisfactorios (verde).

Tabla 11 - Zona Tetlán (Zona 6 de la DGSPG)

\begin{tabular}{|l|l|l|l|}
\hline \multicolumn{1}{|c|}{ Seguridad } & Servicios & \multicolumn{1}{|c|}{ Colonia } & \multicolumn{1}{|c|}{ Trabajo de Campo } \\
\hline Verde & Amarillo & $\begin{array}{l}\text { Jardín de los Poetas y Unidad Ha- } \\
\text { bitacional San Rafael }\end{array}$ & San Rafael \\
\hline Verde & Verde & $\begin{array}{l}\text { Jardín de los Escritores y Jardín de } \\
\text { los Historiadores }\end{array}$ & San Rafael \\
\hline Rojo & Amarillo & San Rafael y Residencial San Rafael & San Rafael \\
\hline Amarillo & Verde & $\begin{array}{l}\text { Jardines de Atemajac y Santa Mó- } \\
\text { nica }\end{array}$ & Santa Elena Alcalde \\
\hline
\end{tabular}




\begin{tabular}{|c|c|c|c|}
\hline Amarillo & Verde & $\begin{array}{l}\text { Jardines del Nilo y Jardines del Nilo } \\
\text { Norte }\end{array}$ & San Rafael \\
\hline Amarillo & Verde & $\begin{array}{l}\text { Unidad Habitacional Vicente Gue- } \\
\text { rrero y Jardines de la Paz Norte }\end{array}$ & San Rafael \\
\hline Amarillo & Rojo & $\begin{array}{l}\text { Unidad habitacional San Rafael y } \\
\text { Jardín de los Poetas }\end{array}$ & San Rafael \\
\hline Amarillo & Amarillo & $\begin{array}{l}\text { Jardines de Atemajac y Santa Mó- } \\
\text { nica }\end{array}$ & Santa Elena Alcalde \\
\hline Rojo & Verde & $\begin{array}{l}\text { Unidad Habitacional los Arraya- } \\
\text { nes, Ramón López Velarde y San } \\
\text { Francisco }\end{array}$ & Lagos de Oriente \\
\hline Amarillo & Rojo & Poblado de Tetlán & Tetlán \\
\hline Rojo & Verde & Jardines San Francisco & Tetlán \\
\hline Amarillo & Amarillo & Obeliscos & Tetlán \\
\hline Amarillo & Amarillo & Aldama Segunda Sección & Tetlán \\
\hline Amarillo & Amarillo & Javier Mina & Tetlán \\
\hline Rojo & Verde & $\begin{array}{l}\text { Hermosa Provincia y Villas del } \\
\text { Nilo }\end{array}$ & Hermosa Provincia \\
\hline Amarillo & Verde & $\begin{array}{l}\text { Insurgentes Tercera Sección y La- } \\
\text { gos de Oriente }\end{array}$ & Tetlán \\
\hline Amarillo & Verde & $\begin{array}{l}\text { Benito Juárez, Infonavit Benito } \\
\text { Juárez y Lagos de Oriente Anexo }\end{array}$ & Lagos de Oriente \\
\hline Amarillo & Verde & $\mathrm{La} \mathrm{Paz}$ & San Rafael \\
\hline Amarillo & Verde & Jardines de La Paz & San Rafael \\
\hline Amarillo & Verde & Jardines de la Paz & San Rafael \\
\hline Amarillo & Amarillo & $\begin{array}{l}\text { Lagos de Oriente Segunda sección, } \\
\text { San Joaquín, Lomas del Gallo y La } \\
\text { Campesina Zona } 6\end{array}$ & Lagos de Oriente \\
\hline
\end{tabular}

Fuente: elaboración propia, con base en; Radiografía Ciudadana de Guadalajara, estudio cualitativo 2007-2008.

La zona El Rosario constituye la de menor número de focos rojos en el ámbito de la seguridad ciudadana, al presentar solo uno en las colonias Antigua Penal de Oblatos / San Felipe (rojo), tal como se desprende de la siguiente tabla; y, a excepción de La Perla y El Mirador (rojo), por un parte, y de Potrero Alto y San Ramón, Olímpica y Atlas Poniente (amarillo), la abrumadora mayoría de los residentes opina positivamente sobre los servicios públicos municipales recibidos (verde). 
TABla 12 - Zona El Rosario (Zona 5 DE la DGSP)

\begin{tabular}{|c|c|c|c|}
\hline Seguridad & Servicios & Colonia & Trabajo de Campo \\
\hline Verde & Verde & $\begin{array}{l}\text { Unidad Habitacional el Rosario y } \\
\text { Rancho Blanco Alamo }\end{array}$ & El Rosario \\
\hline Verde & Verde & Conjunto Habitacional Reforma & El Rosario \\
\hline Amarillo & Verde & La Natividad y San Juan Bosco & San Juan Bosco \\
\hline Amarillo & Verde & San Juan Bosco y La Natividad & San Juan Bosco \\
\hline Verde & Verde & Mirador el Alamo & Olímpica \\
\hline Amarillo & Verde & Rancho Blanco y El Rosario & Olímpica \\
\hline Amarillo & Verde & $\begin{array}{l}\text { Atlas Segunda Sección / Atlas } \\
\text { Poniente }\end{array}$ & Atlas / Olímpica \\
\hline Amarillo & Verde & $\begin{array}{l}\text { Jardines del Rosario / Bosques del } \\
\text { Boulevard }\end{array}$ & Atlas /Olímpica \\
\hline Amarillo & Verde & Esteban Alatorre / Potrero Alto & Felipe Angeles / Olímpica \\
\hline Amarillo & Verde & Los Mártires & Felipe Angeles / Olímpica \\
\hline Amarillo & Verde & Quinta Velarde y González Gallo & Tecnológico / Olímpica \\
\hline Amarillo & Verde & Divina Providencia/ El Real & Medrano / Olímpica \\
\hline Rojo & Verde & $\begin{array}{l}\text { Antigua Penal de Oblatos / San } \\
\text { Felipe }\end{array}$ & $\begin{array}{l}\text { San Felipe, Javier Mina, San } \\
\text { Andrés/ Olímpica }\end{array}$ \\
\hline Amarillo & Amarillo & Potrero Alto y San Ramón & Felipe Angeles / Olímpica \\
\hline Amarillo & Amarillo & Olímpica y Atlas Poniente & Tecnológico y Atlas \\
\hline Amarillo & Rojo & La Perla y El Mirador & San Juan Bosco \\
\hline
\end{tabular}

Fuente: elaboración propia, con base en; Radiografía Ciudadana de Guadalajara, estudio cualitativo 2007-2008.

Por lo tanto, El Rosario se erige como una de las zonas de más alta calidad de vida, siguiendo la percepción ciudadana dominante.

\section{CONCLUSIONES: HACIA UNA RADIOGRAFÍA DE LA SEGURIDAD SUBJETIVA EN GUADALAJARA}

La población del municipio de Guadalajara presenta una tendencia a la baja, de conformidad con las proyecciones a cargo del COEPO, en contraste con sus cinco pares de la ZMG; pero los seis municipios comparten un común denominador, a saber: poco más de la mitad de sus habitantes se sienten inseguros, de acuerdo con el ICESI.

Se trata de la seguridad subjetiva o percepción ciudadana de la seguridad, más allá de las estadísticas oficiales (seguridad objetiva), que en la mayoría de los casos no coinciden; es decir, por un lado, se encuentran los delitos denunciados y, por otro, el sentimiento de seguridad o, por el contrario, de indefensión de las personas. 
Guadalajara no es una ciudad violenta, en términos de homicidios intencionales y delitos a mano armada (tanto en números absolutos como en tasa por 100 mil habitantes) ${ }^{11}$, aunque sí hay signos preocupantes de violencia en el ámbito doméstico (violencia intrafamiliar y suicidios) e institucional (escuelas e institutos educativos públicos y privados, albergues para adultos mayores, centros de salud, incluyendo los de salud mental) y en la propia dinámica de crecimiento de la mancha urbana de la ZMG y evolución de las adicciones (defunciones producto de accidentes viales, consumo excesivo de alcohol y manejo en estado de ebriedad); sin embargo, $20 \%$ de los ciudadanos confiesan sentirse sumamente inseguros y temerosos, evitando incluso salir durante el día. En el otro extremo, cerca de la cuarta parte de la población se considera segura, de acuerdo con el ejercicio Radiografía Ciudadana de Guadalajara.

En rigor, tratándose de la seguridad subjetiva, no existen blancos y negros; antes bien, son los claroscuros o grises los que caracterizan a la percepción social sobre la seguridad de las colonias, barrios y unidades habitacionales en Guadalajara: poco más de la mitad (56\%) de los vecinos aceptan tener una percepción de seguridad poco satisfactoria, pero que no reviste el grado de gravedad como para sentirse temerosos y evitar ciertas rutinas cotidianas.

El esfuerzo llevado a cabo en el campo tampoco permite establecer una correlación clara entre la calidad de los servicios públicos municipales y el sentimiento de seguridad/inseguridad del ciudadano; al verificarse casos de seguridad satisfactoria acompañada por servicios mediocres ó, incluso, de indefensión social al lado de la prestación de servicios óptimos. Lo que sí queda claro es que la mayoría de los habitantes de Guadalajara no se sienten satisfechos en materia de seguridad, y perciben problemas que, si bien son definidos como moderados, de no adoptarse oportunamente políticas, estrategias y líneas de acción gubernamentales, podrían sufrir un proceso de degradación y volverse incontrolables.

Esto es, una radiografía actual de la seguridad ciudadana de Guadalajara arroja datos inquietantes tanto sobre las capacidades del gobierno municipal, como sobre la cultura de la legalidad: insatisfacción de sus habitantes por el estado que guardan la seguridad ciudadana y los principales servicios públicos prestados por el Ayuntamiento, así como déficit social de una cultura de la legalidad, entendida como la convicción de que la ley debería ser la reguladora de la vida comunitaria. A la mediocridad o calidad regular de los servicios y a la percepción ciudadana de una situación de la seguridad pública escasamente satisfactoria, se suma una demanda legítima por los derechos ciudadanos que no va acompañada por las obligaciones que, en contraprestación, se imponen al ciudadano; de los testimonios recogidos entre los vecinos, se verifica una exigencia de derechos, al margen del reconocimiento social de cumplir con los deberes ciudadanos, lo que explica -en parte- la necesidad de fomentar la participación ciudadana, de conformidad con la encuesta Justiciabarómetro, aplicada a los policías municipales preventivos.

Como quiera que sea, la seguridad ciudadana constituye un derecho fundamental, consagrado constitucionalmente; y es en el estado, como detentador del monopolio legítimo de la fuerza, en el que descansa la responsabilidad de esta función pública. Escuchar al pueblo, en su calidad de soberano, debería ser el primer paso para el diseño de una verdadera política pública en la materia; de ahí la relevancia y trascendencia de esta radiografía sobre la seguridad subjetiva en Guadalajara.

\footnotetext{
${ }^{11}$ Para el Dr. Macedonio Tamez Guajardo, ex titular de la DGSPG, la tranquilidad relativa o bajos niveles de violencia de Guadalajara, se explican por la fortaleza de su tejido social; además, se especula en el medio sobre la existencia de un pacto de no agresión entre los diferentes grupos de la delincuencia organizada con presencia en la ZMG. Entrevista realizada el 9 de octubre de 2009 en Guadalajara.
} 
BIBLIOGRAFÍA

http://cuentame.inegi.gob.mx/monografias/informacion/jal/poblacion/default. aspx?tema $=$ me\&e $=14$

http://cuentame.inegi.gob.mx/monografias/informacion/jal/poblacion/distribucion. aspx?tema $=$ me\&e=14 y http://cuentame.inegi.gob.mx/monografias $/$ informacion $/ \mathrm{jal} /$ poblacion/default.aspx?tema $=$ me $\& e=14$

http://coepo.jalisco.gob.mx/index.html; http://coepo.jalisco.gob.mx/html/I_zonametropolitanagdl.html y, COEPO, "Análisis Sociodemográfico para la Zona Metropolitana de Guadalajara”, marzo de 2008, página 7; en, http://coepo.jalisco.gob.mx/PDF/Analisissociodemograficos/Zmg.pdf

http://www.icesi.org.mx/documentos/encuestas/encuestasNacionales/ENSI6_urbana.pdf

http://www.guadalajara.gob.mx/seguridadpublica/zonas-agrupamientos.htm

INEGI; en, http://www.inegi.gob.mx (población fija). COEPO, Vid Supra. Comisión Estratégica de Seguridad Pública y Sistema Estatal de Información sobre Seguridad Pública, Guadalajara, diciembre 2008. 